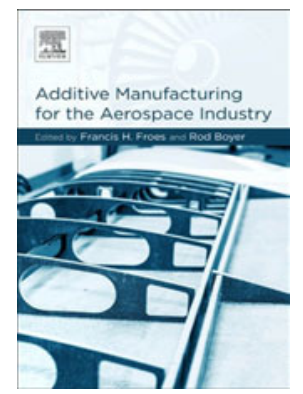

\section{Additive Manufacturing for the Aerospace Industry}

\section{Edited by F. Froes and R. Boyer}

Elsevier, The Boulevard, Langford Lane, Kidlington, Oxford OX5 1GB, UK. 2019. xvi; 465 pp. Illustrated. £175 ISBN 978-0-12814062-8.

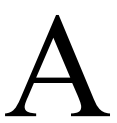
dditive manufacturing (AM) is a game-changing technology. Over the last 25 years, it has made its way from laboratory curiosity to a meaningful production technology and affordable hobbyist workshop tool. I have been fortunate enough to have been actively involved in university research for the latter half of this journey and spent much of this time researching AM for aerospace applications. Characteristic of manufacturing for aerospace applications is the small batch sizes, stringent quality requirements, complexity in design and exotic material usage. These have helped support the drive for aerospace innovation in AM.

Froes and Boyer have assembled contributions from a wide array of leading scholars and industrial users from the world of AM in their book Additive Manufacturing for the
Aerospace Industry. This is a good starting point for the enthusiastic reader from within academia or industry. Aspects from airframe, propulsion and systems manufacture are considered in length following a general overview of the processes currently available. The level of maturity in these areas is well communicated as the opportunity for further research.

There is much in this for the aerospacebiased materials scientist. Many of the challenges in AM for aerospace relate to developing, processing and characterisation materials which are equally fit for process as they are for application. In addition the reader is introduced to emergent topics in this field which relate to in-process inspection and control-widely considered to be one of the limiting factor in wider exploitation of AM for aerospace. This collection is a useful tool for understanding the future of aerospace production techniques and does highlight accurately the challenges airframers and propulsion engineers will face. However, it is important to note that this area is moving so rapidly that I would expect a similar compilation to have a very different feel within 2 years.

A good overview and reference for the curious reader but perhaps of limited value longer term in a rapidly maturing field.

Adam T. Clare

Professor of Manufacturing Engineering University of Nottingham 